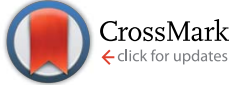

Cite this: RSC Adv., 2017, 7, 3958

Received 2nd December 2016 Accepted 27th December 2016

DOI: 10.1039/c6ra27700d

www.rsc.org/advances

\section{The effect of acid/alkali treatment on the catalytic combustion activity of manganese oxide octahedral molecular sieves $\uparrow$}

\author{
Ming Sun, * Bentian Zhang, Hengfa Liu, Binbin He, Fei Ye, Lin Yu, Changyong Sun \\ and Hongli Wen
}

\begin{abstract}
Manganese oxide octahedral molecular sieves (OMS-2) are a type of widely applied catalyst for its excellent catalytic properties and competitive price. We use $\mathrm{CH}_{3} \mathrm{COOH}$ and $\mathrm{KOH}$ to modify the microstructure, the concentration of $\mathrm{K}^{+}$, the acidity, the redox properties and the oxygen vacancies of the OMS- 2 materials. The acid-treated OMS-2 displays superior catalytic combustion activities in dimethyl ether combustion ( $T_{10}$ of $170{ }^{\circ} \mathrm{C}$ and $T_{90}$ of $230^{\circ} \mathrm{C}, E_{\mathrm{a}}$ of $64.7 \mathrm{~kJ} \mathrm{~mol}^{-1}$ ) and toluene combustion $\left(T_{10}\right.$ of $170{ }^{\circ} \mathrm{C}$ and $T_{90}$ of $194^{\circ} \mathrm{C}, E_{\mathrm{a}}$ of $62.4 \mathrm{~kJ} \mathrm{~mol}^{-1}$ ), whereas the alkali treatment imposes a negative effect on the catalytic activity. The superior activity of the acid-treated OMS-2 can be ascribed to the richer surface oxygen, higher oxygen mobility and redox properties, and stronger acidic sites of the catalyst.
\end{abstract}

\section{Introduction}

$\mathrm{MnO}_{2}$ presents a wide diversity of morphologies and crystal structures, including $\alpha-, \beta-, \gamma-, \delta-, \varepsilon-\mathrm{MnO}_{2}$, etc. Among these polymorphic forms, manganese oxide octahedral molecular sieves (OMS-2), namely the cryptomelane structure of $\alpha-\mathrm{MnO}_{2}$, has attracted special attention for its outstanding properties such as low cost, multiple sources, porous structure, mixed valance of Mn, and notable redox activity. ${ }^{\mathbf{1 , 2}}$ This material has found wide application in the field of catalysis and electrochemistry (supercapacitors, lithium-ion batteries, fuel cells, etc. ${ }^{3,4}$ ). As for the application in catalysis, especially in the domain of environmental science, the OMS-2 catalyst has been extensively studied for oxidation of $\mathrm{CO}, \mathrm{O}_{3}$ and soot, ${ }^{5-8}$ and the volatile organic carbon compounds (formaldehyde and acetaldehyde, ${ }^{9,10}$ ethanol, ${ }^{11}$ benzene, ${ }^{12}$ toluene, ${ }^{13-15}$ hexachlorobenzene, ${ }^{16}$ ethyl acetate, ${ }^{17,18} o$-xylene, ${ }^{19}$ etc. $)$.

To improve the catalytic activity of the OMS-2 material, doping with the transition metal or noble metal (Fe, $\mathrm{Co}, \mathrm{Ni}, \mathrm{Cu}$, $\mathrm{Ce}, \mathrm{Ag}, \mathrm{Pd}, \mathrm{Zr}^{\mathbf{1 0}, \mathbf{2 0}-27}$ ), is one of the most effective approaches. The doping measurement can modify the surface/structure properties of OMS-2, especially the redox activity, which could lead to an enhancement in the catalytic performance. In this study, we used a facile way to modify the OMS-2 material. The OMS-2 catalyst was simply treated with the solution of inorganic

Key Laboratory of Clean Chemistry Technology of Guangdong Regular Higher Education Institutions, School of Chemical Engineering and Light Industry, Guangdong University of Technology, 510006 Guangzhou, P. R. China. E-mail: sunmgz@gdut.edu.cn; Fax: +86-20-39322231; Tel: +86-20-39322202

$\dagger$ Electronic supplementary information (ESI) available. See DOI: $10.1039 / \mathrm{c} 6 \mathrm{ra} 27700 \mathrm{~d}$ acid $\left(\mathrm{CH}_{3} \mathrm{COOH}, \mathrm{HAc}\right)$ or alkali $(\mathrm{KOH})$. The treatment protocol is fixed by considering the following evidences: (1) the OMS-2 contains $2 \times 2$ tunnel structure with $\mathrm{K}^{+}$in the tunnel, and the $\mathrm{K}^{+}$concentration can affect the catalytic and electrochemical activity. ${ }^{28,29}$ Therefore, it is possible to adjust the catalytic property through the substitution of $\mathrm{K}^{+}$by other alkali metal ions ( $\mathrm{Li}, \mathrm{Na}, \mathrm{Cs}$ ) or $\mathrm{H}^{+}{ }^{\mathbf{1 7 , 1 8 , 2 1 , 3 0 , 3 1}}$ (2) The etching by acid. Metal oxides have some special O-terminated facets which could react with $\mathrm{H}^{+}$. The post etching process has been applied to obtain high performance $\gamma-\mathrm{MnO}_{2}$-like material by selective dissolution of $\mathrm{LaMnO}_{3}$ with $\mathrm{HNO}_{3},{ }^{32}$ to create with newly formed oxygen defect over the surface of $\mathrm{La}_{0.5} \mathrm{Sr}_{0.5} \mathrm{CoO}_{3},{ }^{33}$ to produce highly defective $\mathrm{CeO}_{2}$ by $\mathrm{HNO}_{3},{ }^{34}$ to modify the micro-surface of $\mathrm{Cu}_{2} \mathrm{O}$ forming pinhole or zigzag with acetic acid, ${ }^{35}$ and to restructure $\mathrm{Co}_{3} \mathrm{O}_{4}$ from polycrystalline microspheres to single-crystalline polyhedra by HAc, ${ }^{36}$ etc. Through the acid/alkali treatment, we aimed to control the $\mathrm{K}^{+}$concentration and to modify the OMS-2 structure forming defects or oxygen vacancies, thus achieving an enhanced catalytic activities.

Catalytic combustion is an important technology used widely in the field of energy-transforming and environmental protection. Catalytic combustion could promote the combustion efficiency and decrease the discharge of $\mathrm{CO}$ and hydrocarbons in the combustion of methane, ${ }^{37}$ LPG or dimethyl ether (DME). Catalytic combustion is also an effective technology to eliminate volatile organic compounds (VOCs). Among the materials for catalytic combustion, manganese oxides have been considered as the promising low-temperature catalyst. To evaluate the effect of the acid/alkali treatment on OMS-2, herein, we applied the OMS-2 catalysts in the catalytic combustion of DME and toluene, respectively, and discussed the relationship between surface/structure properties and their catalytic performance. 


\section{Experimental}

All of the chemical reagents were of analytical grade and were used as received without further purification. $\mathrm{KMnO}_{4}, \mathrm{MnSO}_{4}{ }^{-}$ $\cdot \mathrm{H}_{2} \mathrm{O}, \mathrm{HNO}_{3}(68 \%), \mathrm{CH}_{3} \mathrm{COOH}(\mathrm{HAc}), \mathrm{KOH}$ were all purchased from Guangzhou Chemical Reagent Company.

\subsection{Catalysts preparation}

The OMS-2 material was prepared by a refluxing methods as reported previously. ${ }^{38}$ The $\mathrm{KMnO}_{4}$ solution was added into an acidified $\mathrm{MnSO}_{4}$ solution to achieve a $\mathrm{MnO}_{4}{ }^{-} / \mathrm{Mn}^{2+}$ molar ratio of 0.76 . The mixtures were then refluxed at $100{ }^{\circ} \mathrm{C}$ for $24 \mathrm{~h}$. After the reaction, the product was filtered, washed with deionized water thoroughly, and then dried at $60{ }^{\circ} \mathrm{C}$ overnight to get final sample.

2.1.1 Acid-treated OMS-2. The prepared OMS- 2 was added into $1 \mathrm{~mol} \mathrm{~L}^{-1} \mathrm{HAc}$ solution, stirred and refluxed at $60^{\circ} \mathrm{C}$ under atmosphere for $24 \mathrm{~h}$. Then, the resulting black slurry was filtered, washed thoroughly by deionized water, and dried at $60{ }^{\circ} \mathrm{C}$ overnight to get the final product. The OMS-2 material obtained by this way was denoted as HAc-OMS-2.

2.1.2 Alkali-treated OMS-2. The alkali-treated OMS-2 was prepared in a similar way as that of the acid treatment, except that the acid was substituted by $1 \mathrm{~mol} \mathrm{~L}^{-1} \mathrm{KOH}$ for $6 \mathrm{~h}$. The obtained sample was denoted as $\mathrm{KOH}-\mathrm{OMS}-2$.

\subsection{Materials characterization}

The X-ray diffraction patterns (XRD) were characterized with a MSAL-XDII X-ray diffractometer $(40 \mathrm{kV}, 20 \mathrm{~mA}, \mathrm{Cu} \mathrm{K} \alpha$ radiation) at a scan rate of $5^{\circ} \mathrm{min}^{-1}$. The data were collected at a $0.01^{\circ}$ step from $10^{\circ}$ to $80^{\circ}$. The scanning electron microscopy (SEM) images were obtained by using SU8020 instrument. The high-resolution transmission electron microscopy (HRTEM) images were recorded on a FEI Tecnai G20 operating at an accelerating voltage of $200 \mathrm{kV}$. Temperature programmed reduction of hydrogen $\left(\mathrm{H}_{2}\right.$-TPR) and oxygen desorption $\left(\mathrm{O}_{2}-\right.$ TPD) measurement were carried out on a Micromeritics AutoChem 2920 chemisorption analyzer equipped with a TCD detector. For TPR test, about $30 \mathrm{mg}$ of sample was loaded in a Ushaped tube and pretreated at $200{ }^{\circ} \mathrm{C}$ in a flow of Ar for $1 \mathrm{~h}$. After cooling to room temperature, the catalyst was then heated at a rate of $10^{\circ} \mathrm{C} \mathrm{min}^{-1}$ to $600{ }^{\circ} \mathrm{C}$ in a flowing mixture of $\mathrm{H}_{2}$ and $\mathrm{Ar}$

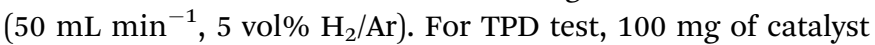
was pretreated under $\mathrm{He}$ atmosphere at $300{ }^{\circ} \mathrm{C}$ for $30 \mathrm{~min}$, and then cooled to room temperature, followed by exposing to $\mathrm{O}_{2}$ for $30 \mathrm{~min}$. Then, it was blown using He to remove the physically absorbed oxygen and subsequently heated to $900{ }^{\circ} \mathrm{C}$ in flowing He. Ammonia temperature-programmed desorption ( $\left.\mathrm{NH}_{3}-\mathrm{TPD}\right)$ measurement was carried out by a Quantachrome instrument. For $\mathrm{NH}_{3}$-TPD, $100 \mathrm{mg}$ of the sample was preheated in a flow of dry $\mathrm{N}_{2}$ at $350{ }^{\circ} \mathrm{C}$ for $1 \mathrm{~h}$ in a fixed-bed quartz flow reactor. After preheating, $\mathrm{NH}_{3}$ adsorption was done at room temperature by passing $1000 \mathrm{ppm} \mathrm{NH}_{3}$ in $\mathrm{N}_{2}$ gas mixture at a flow rate of 150 $\mathrm{mL} \min ^{-1}$ for $90 \mathrm{~min}$. The sample was then flushed with a steady flow of $\mathrm{N}_{2}$ to remove the surface physically adsorbed $\mathrm{NH}_{3}$. After the flushing, the catalyst was heated under a flow of
$\mathrm{N}_{2}$ from room temperature to $450{ }^{\circ} \mathrm{C}$ with a temperature ramp of $10^{\circ} \mathrm{C} \mathrm{min}^{-1}$. X-ray photoelectron spectroscopy (XPS) data was obtained by a VG MultiLab 2000 electron spectrometer with an $\mathrm{Mg} \mathrm{K} \alpha \mathrm{X}$-ray source. The spectra were calibrated using the carbon peak. The spectra were deconvoluted using the XPSPEAK software. The element compositions were analyzed by inductively coupled plasma-atomic emission spectroscopy (ICP-AES, PROFILE SPEC).

\subsection{Catalytic activity}

The catalytic combustion of DME was tested at atmospheric pressure in a continuous flow fixed-bed quartz reactor $(8 \mathrm{~mm}$ i.d.). $100 \mathrm{mg}$ of the catalyst was loaded in the middle of the reactor supported by quartz wool. The catalysts (40-60 meshes) were pretreated for $1 \mathrm{~h}$ with $20 \% \mathrm{O}_{2}$ in $\mathrm{He}$ at $250{ }^{\circ} \mathrm{C}$, followed by cooling to the reaction temperature in the same gas. A gas mixture of DME, oxygen and helium were co-feed into the reactor with the volume ratio of $1: 10: 40$, and the total gas hourly space velocity (GHSV) was fixed at $30000 \mathrm{~h}^{-1}$. The outflow gas was analyzed using Agilent 6820 gas chromatograph, with a methyl silicone capillary column (ATSE-30) connected to a flame ionization detector.

The catalytic combustion of toluene was tested in a similar equipment. The loading catalyst was also $100 \mathrm{mg}$. The concentration of toluene was $4 \mathrm{~g} \mathrm{~m}^{-3}$ and the GHSV was 20000 $\mathrm{h}^{-1}$. The catalytic activity is characterized by parameter $T_{10}$ and $T_{90}$, indicating the temperature at which DME or toluene conversion reaches $10 \%$ and $90 \%$, respectively.

\section{Results and discussion}

\subsection{Structure and surface properties of the OMS-2 catalysts}

The crystal structure and the phase purity of the catalysts were investigated by XRD as shown in Fig. 1. All the patterns match well with the tetragonal cryptomelane structures of $\alpha-\mathrm{MnO}_{2}$ (JCPDS 44-0141). After the acid or alkali treatment, no obvious difference among these XRD peaks is observed, indicating that these treatments do not affect the phase structure of the OMS-2 catalysts.

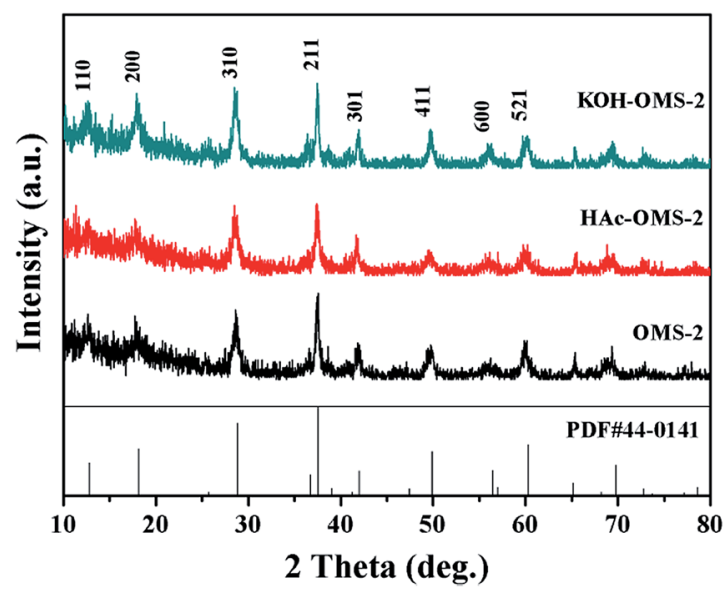

Fig. 1 XRD patterns of the OMS-2 catalysts. 
The typical SEM images and the element-mapping results for OMS-2, HAc-OMS-2, and KOH-OMS-2 are displayed in Fig. 2. All of the samples display nanorods morphologies regardless of the acid or the alkali treatment. The element-mapping results show the uniform and continuous dispersion of the $\mathrm{K}, \mathrm{Mn}$ and $\mathrm{O}$ elements. However, the relative content of $\mathrm{K}$ is different: for OMS-2, it is $5.5 \%$ (wt.); for $\mathrm{KOH}-\mathrm{OMS}-2$, it rises to $8.6 \%$ (wt.); for HAc-OMS-2, it decreases to $4.5 \%$ (wt.).

TEM images reveal that the three catalysts are characterized by the morphology of nanorods (Fig. 3), which is consistent with the results of the SEM. The lattice fringes in the HRTEM images show $d$-spacing of $0.69 \mathrm{~nm}$, corresponding to the (110) facet of $\alpha-\mathrm{MnO}_{2}$. By careful inspection, it can be found that the lattice fringes of the OMS-2 and KOH-OMS-2 are more clear than those of the HAc-OMS-2, indicating that the former two catalysts are highly crystallized, while the HAc-OMS-2 has poor crystal structure with many defects as displayed in Fig. S1 (ESI $\dagger$ ).

The $\mathrm{H}_{2}$-TPR characterizations were applied to examine the surface and bulk oxygen reducibility of the $\mathrm{MnO}_{2}$ catalysts, and the result is presented in Fig. 4a. All the three catalysts display overlapping reduction peaks, which contain the reduction of $\mathrm{MnO}_{2}$ to $\mathrm{Mn}_{2} \mathrm{O}_{3}$ and then to $\mathrm{MnO}^{39,40}$ The temperatures of the reduction peak for the OMS-2, HAc-OMS-2 and KOH-OMS-2 are ca. $321{ }^{\circ} \mathrm{C}, 273{ }^{\circ} \mathrm{C}$ and $348{ }^{\circ} \mathrm{C}$, respectively. The reduction temperature of the $\mathrm{MnO}_{2}$ reflects its reducibility, ${ }^{6}$ therefore, the reducibility of the OMS-2 decreases in the order of HAc-OMS-2> OMS-2> KOH-OMS-2. The amounts of $\mathrm{H}_{2}$ consumption are summarized in Table 1. Compared with the OMS-2 catalyst, the $\mathrm{H}_{2}$ consumption of HAc-OMS-2 drops, however, it rises in the case of $\mathrm{KOH}-\mathrm{OMS}-2$. The smaller $\mathrm{H}_{2}$ consumption means the lower average oxidation state (AOS), indicating that there is more $\mathrm{Mn}^{3+}$ in the HAc-OMS-2 than the two other catalysts.
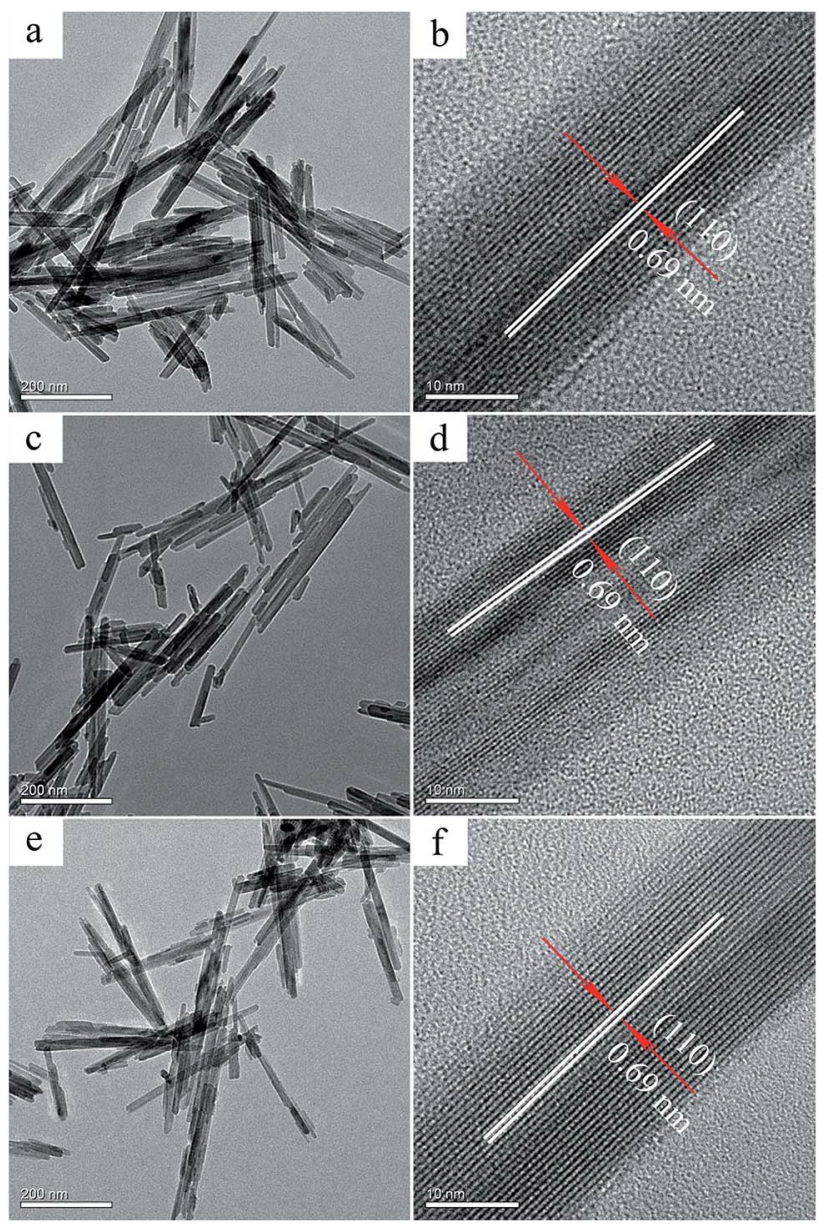

Fig. 3 TEM and HRTEM images of the OMS-2 ( $a$ and b), HAc-OMS-2 (c and d), $\mathrm{KOH}-\mathrm{OMS}-2$ (e and f).
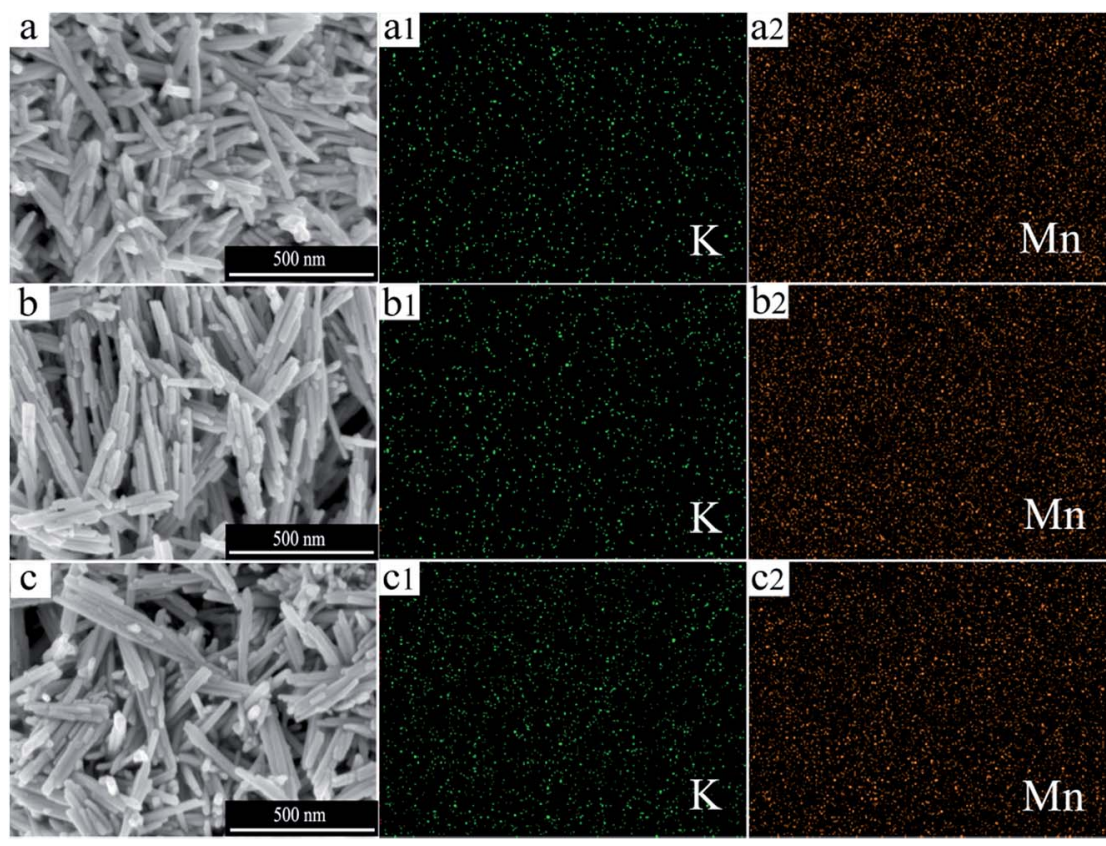

a3
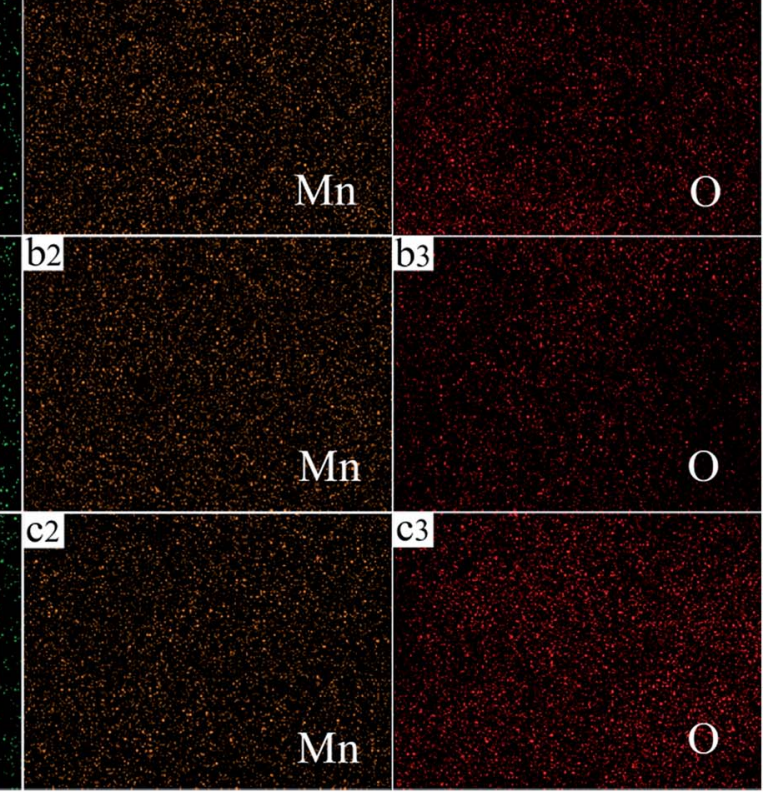

Fig. 2 FESEM images and element mapping of the OMS-2 (a), HAc-OMS-2 (b), KOH-OMS-2 (c). 

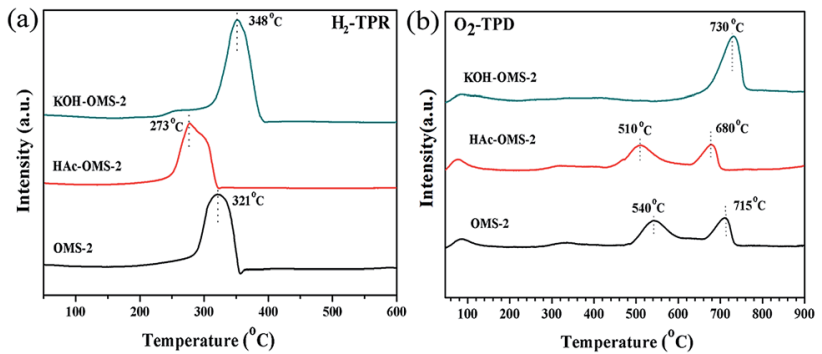

Fig. $4 \mathrm{H}_{2}$-TPR (a) and $\mathrm{O}_{2}$-TPD (b) profiles of the OMS-2 catalysts.

The $\mathrm{O}_{2}$-TPD tests were conducted to explore the oxygen species involved in the catalytic combustion reaction (Fig. 4b). Generally, three oxygen desorption peaks are detected in the $\mathrm{O}_{2}$ TPD profiles of the OMS-2 catalysts except that of the $\mathrm{KOH}-$ OMS-2: low temperature (LT, $<200{ }^{\circ} \mathrm{C}$ ), medium temperature (MT, 400-600 ${ }^{\circ} \mathrm{C}$ ), and high temperature (HT, >600 ${ }^{\circ} \mathrm{C}$ ), which can be ascribed to the surface oxygen species or chemisorbed oxygen molecule, the surface lattice oxygen related with $\mathrm{Mn}$ (III), and the bulk lattice oxygen related with $\mathrm{Mn}(\mathrm{IV}),{ }^{6,22,40}$ respectively. Among the three OMS-2 catalysts, the HAc-OMS-2 has a relatively lower desorption peak for the MT and HT peaks. In the case of KOH-OMS-2, the MT peak disappears and the HT peak becomes stronger, delayed at least $15{ }^{\circ} \mathrm{C}$ compared with the OMS- 2 catalyst. In conclusion, the temperature of $\mathrm{O}_{2}$ desorption for the HAc-OMS-2 catalyst was the lowest, suggesting that it possesses the most loosely bound and active oxygen species.

The surface acidity of the $\mathrm{MnO}_{2}$ is known to be related with its catalytic activity, and $\mathrm{NH}_{3}$-TPD experiments were performed to explore the surface acidity (Fig. 5 and Table 1). For the three OMS-2 catalysts, two continuous desorption peaks of $\mathrm{NH}_{3}$ can be observed from $170{ }^{\circ} \mathrm{C}$ to $320{ }^{\circ} \mathrm{C}$. The desorption peak temperature indicates the binding strength between acid sites and $\mathrm{NH}_{3}$ molecule, ${ }^{\mathbf{4 1}}$ therefore, the lower temperature corresponds to weak acidic site, and the higher temperature stands for strong acidic site. Compared with the origin OMS-2 catalyst, the HAc treated OMS-2 has a relatively higher desorption temperature of $\mathrm{NH}_{3}$ and larger desorption peak area, revealing that the acid strength, especially the strong acid, rises after the acid treatment. Whereas, after the $\mathrm{KOH}$ treatment, the acidity of OMS-2 decreases significantly as shown by the small desorption peak area and the low peak position. The OMS-2 is reported to have Brönsted acid sites and Lewis acid sites, the former are originated from acidic hydroxyl groups attached to metal oxides $(\mathrm{Mn}-\mathrm{OH})$, and the latter is regarded as empty orbitals of metal

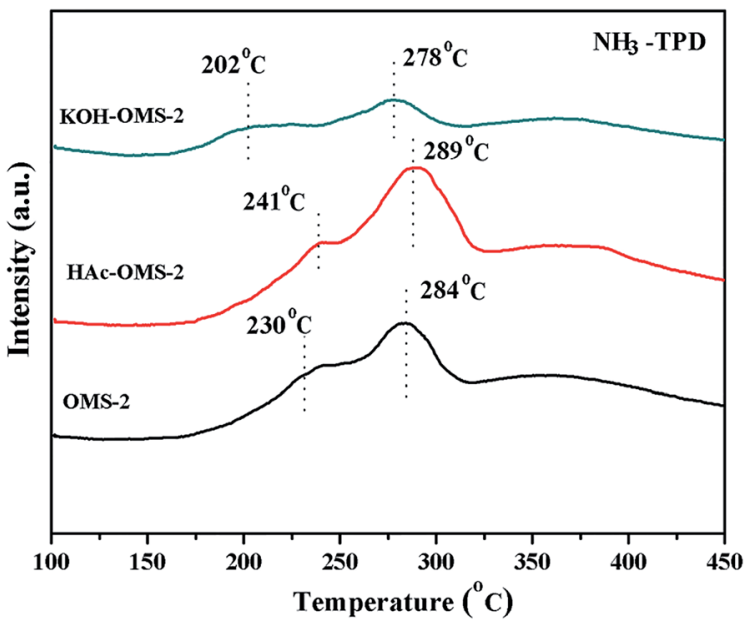

Fig. $5 \mathrm{NH}_{3}$-TPD profiles of the OMS-2 catalysts.

ions in the $\mathrm{MnO}_{2} \cdot{ }^{42}$ During the process of HAc treatment, the $\mathrm{K}$ in the tunnel of OMS-2 is gradually exchanged by $\mathrm{H}^{+}$as proved by the ICP result (Table 2), and the $\mathrm{H}^{+}$exchange increases the Brönsted acid sites. ${ }^{31}$ In another aspect, the acid treatment creates more oxygen vacancy sites over the OMS-2 material as justified by the XPS results (Fig. 6) in latter chapter. The Lewis acid sites increases with the rise of oxygen vacancy sites. ${ }^{43}$ In general, the acid treatment enhances the Brönsted/Lewis acid sites of the OMS-2 catalysts. In contrast, the $\mathrm{KOH}$ treatment decreases the Brönsted acid sites by the reaction of protons with hydroxide.

The XPS characterization was used to study the surface properties of the OMS- 2 catalysts. The XPS result is displayed in Fig. 6 and Table 2. As shown in Table 2, the surface K/Mn molar ratio of OMS-2 is 0.15. After HAc treatment, it drops to 0.13. However, after the alkali treatment, the $\mathrm{K} / \mathrm{Mn}$ rises to 0.36 . The bulk K/Mn molar ratios of the three OMS-2 catalysts tested by ICP are also presented in Table 2, and they exhibit a similar trend.

The average oxidation state (AOS) of Mn in the OMS- 2 catalysts were calculated based on the Mn 3s spectra (Fig. 6a) and listed in (Table 2). The calculated AOS increases in the sequence of HAc-OMS-2 (3.62) < OMS-2 (3.75) < KOH-OMS-2 (3.88), further confirming that there is more $\mathrm{Mn}^{3+}$ in the acid-treated OMS-2 than in the two other catalysts. The calculated Mn 3s results match well with the TPR tests.

Fig. $6 \mathrm{~b}$ shows the Mn 2 $\mathrm{p}_{3 / 2}$ spectra of the OMS-2 catalysts. Slight difference in the binding energy (BE) of the $\mathrm{Mn} 2 \mathrm{p}_{3 / 2}$ is

Table 1 Reducibility, $\mathrm{H}_{2}$-TPR, $\mathrm{O}_{2}-$ TPD and $\mathrm{NH}_{3}-\mathrm{TPD}$ results of the catalysts

\begin{tabular}{|c|c|c|c|c|c|}
\hline \multirow[b]{2}{*}{ Samples } & \multirow[b]{2}{*}{$\begin{array}{l}\mathrm{H}_{2}-\mathrm{TPR} \\
\text { peak } /{ }^{\circ} \mathrm{C}\end{array}$} & \multirow[b]{2}{*}{$\begin{array}{l}\mathrm{H}_{2} \text { consumption } \\
\mathrm{mmol} \mathrm{g}^{-1}\end{array}$} & \multirow[b]{2}{*}{$\begin{array}{l}\mathrm{O}_{2}-\mathrm{TPD} \\
\text { peak } /{ }^{\circ} \mathrm{C}\end{array}$} & \multicolumn{2}{|l|}{$\mathrm{NH}_{3}-\mathrm{TPD}$} \\
\hline & & & & Position $/{ }^{\circ} \mathrm{C}$ & $\begin{array}{l}\text { Peak area } \\
\text { (a.u.) }\end{array}$ \\
\hline OMS-2 & 321 & 7.8 & $540 / 715$ & $230 / 284$ & 2357 \\
\hline HAc-OMS-2 & 273 & 6.5 & $510 / 680$ & $241 / 289$ & 2583 \\
\hline $\mathrm{KOH}-\mathrm{OMS}-2$ & 348 & 8.6 & 730 & $202 / 278$ & 1299 \\
\hline
\end{tabular}


Table 2 AOS of Mn, surface element compositions, catalytic activity and apparent activation energies $\left(E_{\mathrm{a}}\right)$ of OMS-2 catalysts

\begin{tabular}{|c|c|c|c|c|c|c|c|c|c|c|c|}
\hline & \multicolumn{2}{|c|}{$\mathrm{K} / \mathrm{Mn}(\mathrm{mol})$} & \multicolumn{3}{|l|}{ XPS } & \multicolumn{3}{|c|}{ DME combustion activity and $E_{\mathrm{a}}$} & \multicolumn{3}{|c|}{$\begin{array}{l}\text { Toluene combustion activity and } \\
E_{\mathrm{a}}\end{array}$} \\
\hline & $\mathrm{Bulk}^{a}$ & Surface $^{b}$ & $\begin{array}{l}\mathrm{Mn}^{3+} / \mathrm{Mn}^{4+c} \\
(\mathrm{~mol})\end{array}$ & $\begin{array}{l}\mathrm{O}_{\text {ads }} / \mathrm{O}_{\text {latt }}{ }^{c} \\
(\mathrm{~mol})\end{array}$ & $\operatorname{AOS}^{d}$ & $T_{10}\left({ }^{\circ} \mathrm{C}\right)$ & $T_{90}\left({ }^{\circ} \mathrm{C}\right)$ & $\begin{array}{l}E_{\mathrm{a}} \\
\left(\mathrm{kJ} \mathrm{mol}^{-1}\right)\end{array}$ & $T_{10}\left({ }^{\circ} \mathrm{C}\right)$ & $T_{90}\left({ }^{\circ} \mathrm{C}\right)$ & $\begin{array}{l}E_{\mathrm{a}} \\
\left(\mathrm{kJ} \mathrm{mol}^{-1}\right)\end{array}$ \\
\hline OMS-2 & 0.10 & 0.15 & 0.83 & 0.58 & 3.75 & 187 & 256 & 70.4 & 178 & 203 & 66.3 \\
\hline HAc-OMS-2 & 0.095 & 0.13 & 1.58 & 0.76 & 3.62 & 170 & 230 & 64.7 & 170 & 194 & 62.4 \\
\hline
\end{tabular}

${ }^{a}$ Obtained from the ICP results. ${ }^{b}$ Calculated from the XPS results. ${ }^{c}$ Based on the fitting result of the XPS. ${ }^{d}$ Calculated with the formula: AOS $^{44}=$ 8.95-1.13 $\times \Delta E_{\mathrm{s}}$, where the $\Delta E_{\mathrm{s}}$ is the splitting energy of the Mn 3s.

observed among the three catalysts. For OMS-2, the peak of Mn $2 \mathrm{p}_{3 / 2}$ locates at $c a$. $642.42 \mathrm{eV}$. After acid or alkali treatment, the $\mathrm{BE}$ shifts to the high energy, especially for the alkali-treated OMS-2, the BE moves to $641.87 \mathrm{eV}$, demonstrating that there is a larger amount of higher valence $\mathrm{Mn}$ in the $\mathrm{KOH}-\mathrm{OMS}-2$ catalyst. This result agrees well with the AOS result. Similar phenomena was reported by Suib et $a .^{45}$ about the $\mathrm{Cu}$ doped manganese oxide. The prepared $\mathrm{CuMnO}_{x}-\mathrm{B}$ sample exhibited the most active performance for CO oxidation, and the Mn $2 \mathrm{p}_{3 / 2}$ shifted to lower energy side. The Mn $2 \mathrm{p}_{3 / 2}$ spectra is fitted into two peaks. One is around $642.0 \mathrm{eV}$, and the other is $c a .643 .3 \mathrm{eV}$, and they are ascribed to the $\mathrm{Mn}^{3+}$ and $\mathrm{Mn}^{4+}$ species, respectively. The Mn 2p result indicates the co-existence of $\mathrm{Mn}^{3+}$ and $\mathrm{Mn}^{4+}$ in the catalysts. As shown in Table 2, the HAc-OMS-2 catalyst possess the highest $\mathrm{Mn}^{3+} / \mathrm{Mn}^{4+}$ atomic ratio (1.58), followed by OMS-2 (0.83), while $\mathrm{KOH}-\mathrm{OMS}-2$ has the lowest $\mathrm{Mn}^{3+} / \mathrm{Mn}^{4+}$ atomic ratio (0.68).

Fig. $6 \mathrm{c}$ displays the $\mathrm{O} 1 \mathrm{~s}$ results of the catalysts. The $\mathrm{O} 1 \mathrm{~s}$ spectra is deconvoluted into two subpeaks. The binding energy at $529.8 \mathrm{eV}$ corresponds to the lattice oxygen species $\left(\mathrm{O}_{\text {latt }}\right)$, and the binding energy at $531.3 \mathrm{eV}$ can be assigned to surface adsorbed oxygen $\left(\mathrm{O}_{\text {ads }}\right)$. The $\mathrm{O}_{\text {ads }} / \mathrm{O}_{\text {latt }}$ molar ratios are summarized in Table 2. From Table 2, we can see that the $\mathrm{O}_{\text {ads }} /$ $\mathrm{O}_{\text {latt }}$ molar ratios of the catalysts decreases in the order of HAcOMS-2 (0.76) > OMS-2 (0.58) > KOH-OMS-2 (0.27). This might be related to the poor crystal structure with more surface defects of HAc-OMS-2 as observed in HRTEM (Fig. 3d and S1 $\dagger$ ). The $\mathrm{O} 1 \mathrm{~s}$ binding energy of the OMS-2, HAc-OMS-2, and KOH-OMS-2 locates at 529.9, 529.9, and $529.4 \mathrm{eV}$, respectively. Noted that the $\mathrm{O} 1 \mathrm{~s}$ BE of $\mathrm{KOH}-\mathrm{OMS}-2$ shifts to lower energy side, and this confirms that there is more lattice oxygen species in the $\mathrm{KOH}-$ OMS-2 catalyst. The surface adsorbed oxygen is relevant to the surface oxygen vacancy. ${ }^{\mathbf{4 1 , 4 6}}$ Therefore, it can be deduced from the above results that the density of the surface oxygen vacancy is the highest in the HAc-OMS-2 among the three catalysts.

\subsection{Catalytic performance and discussion}

To examine how the acid/alkali treatment influence the catalytic property of the OMS-2 catalysts, catalytic combustion of new energy dimethyl ether (DME) and typical air pollutant toluene were performed. The DME catalytic combustion activity over the three catalysts with a GHSV of $30000 \mathrm{~mL} \mathrm{~g}^{-1} \mathrm{~h}^{-1}$ is presented in Fig. 7 and Table 2, the combustion activities follow the sequence of HAc-OMS-2 > OMS-2 > KOH-OMS-2. The KOHOMS-2 exhibits the lowest catalytic activity, and its $T_{10}$ and $T_{90}$ is $200{ }^{\circ} \mathrm{C}$ and $267{ }^{\circ} \mathrm{C}$, respectively. After the acid treatment, a significant decreases (about $30^{\circ} \mathrm{C}$ ) in $T_{10}$ and $T_{90}$ is discovered for the HAc-OMS-2 catalyst. The HAc-OMS-2 exhibits the highest catalytic activity among the three catalysts with a $T_{10}$ of $170{ }^{\circ} \mathrm{C}$ and a $T_{90}$ of $230{ }^{\circ} \mathrm{C}$. For comparison, the performance of DME combustion previously reported are summarized in Table $\mathrm{S} 1$ (ESI $\dagger$ ). From the Table $\mathrm{S} 1, \dagger$ we can see that the performance ( $T_{10}$ and $T_{90}$ ) of the HAc-OMS-2 is comparable to those of the reported catalyst. These results clearly show that the acid treatment on the OMS-2 has positive effect on the catalytic performance. However, the alkali treatment brings negative effluence on the catalytic performance.

The catalytic combustion of toluene over these catalysts was also conducted to study that the OMS-2 material has wide
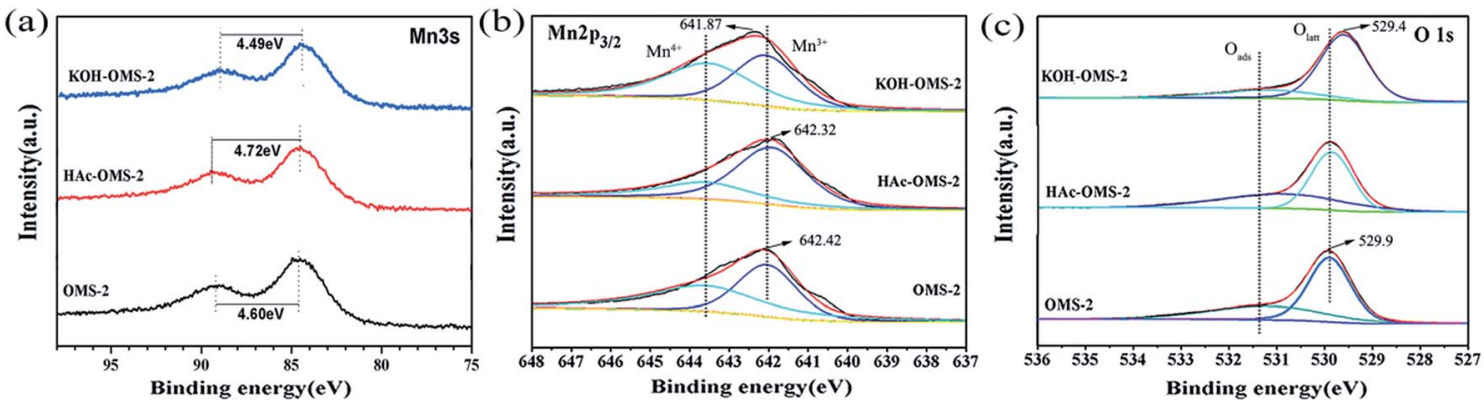

Fig. 6 XPS spectra of (a) Mn 3s, (b) Mn 2p $p_{3 / 2}$, and (c) O 1s for the OMS-2 catalysts. 

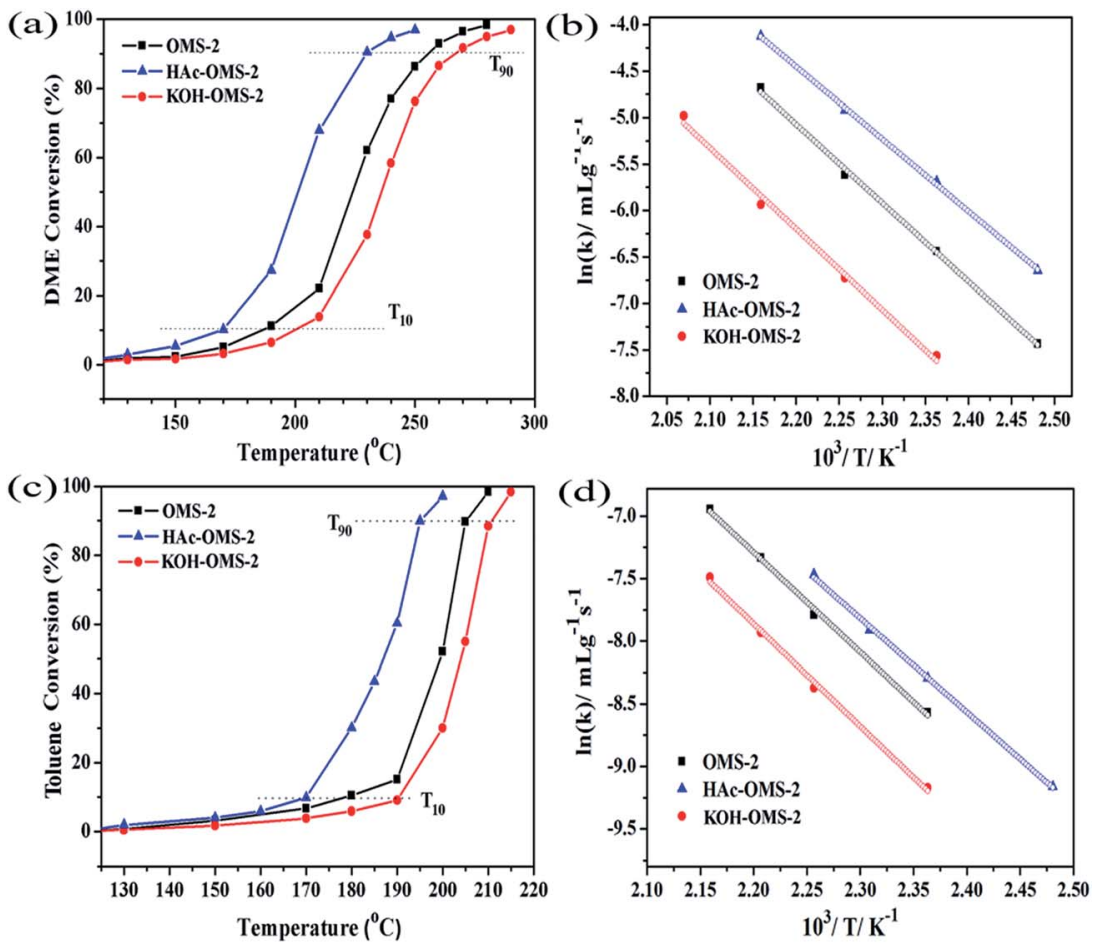

Fig. 7 (a) Activity profiles and (b) Arrhenius plots of the DME catalytic combustion at GHSV $=30000 \mathrm{~mL} \mathrm{~g}^{-1} \mathrm{~h}^{-1}$, (c) activity profiles and (d) Arrhenius plots of the toluene catalytic combustion at GHSV $=20000 \mathrm{~mL} \mathrm{~g}^{-1} \mathrm{~h}^{-1}$.

application as combustion catalyst (Fig. 7c and Table 2). As shown in Table 2, the order of the toluene combustion is identical to that of the DME combustion. Among them, HAc-OMS-2 shows the best catalytic performance with a $T_{10}$ and $T_{90}$ of $170{ }^{\circ} \mathrm{C}$ and $194{ }^{\circ} \mathrm{C}$, respectively. The OMS-2 is less active with the $T_{10}$ of $178^{\circ} \mathrm{C}$ and the $T_{90}$ of $203{ }^{\circ} \mathrm{C}$. The KOH-OMS-2 exhibits the lowest catalytic activity, giving the $T_{10}$ of $190{ }^{\circ} \mathrm{C}$ and the $T_{90}$ of $210^{\circ} \mathrm{C}$. Some of the reported metal oxide catalysts for toluene combustion are listed in Table S2 (ESI $\dagger$ ). Apparently, the performance of the HAcOMS-2 catalyst is comparable to those of the reported catalyst.

Based on the above experiments, the acid-treated OMS-2 displayed superior catalytic combustion activities, no matter in the DME combustion or in the toluene combustion, while, the alkali-treated OMS-2 showed inferior performance. The effects of important properties related to the catalytic functions are discussed below:

3.2.1 Reductivity. As shown in Table 1 and Fig. 4a, the reductivity of the three catalysts decreases in the order of HAcOMS-2 > OMS-2 > KOH-OMS-2, which is in accordance with their respective catalytic activities. The higher reducibility of a catalyst usually means higher oxygen species mobility, which facilitates the redox process and leads to a better catalytic performance., ${ }^{9,10,24,47}$ The HAc-OMS-2 has the lowest reduction temperature and the highest oxygen mobility, consequently, it shows the best catalytic performance.

3.2.2 Oxygen vacancy and oxygen species. Based on the $\mathrm{H}_{2}$ consumption results and the AOS and Mn $2 p$ deconvolution, it is found that the fraction of $\mathrm{Mn}^{3+}$ in the HAc-OMS-2 is higher than that of the two other OMS-2 catalysts. The presence of
$\mathrm{Mn}^{3+}$ is associated with the creation of oxygen vacancies, ${ }^{48,49}$ therefore, the concentration of oxygen vacancies in HAc-OMS-2 is relatively higher than its counterparts. The oxygen vacancies have vital impact on the catalytic performance. Increasing the concentration of oxygen vacancies can improve the catalytic performance of $\mathrm{MnO}_{2},{ }^{50}$ and this mechanism has been reported in the oxidation of benzene ${ }^{48}$ aerobic alcohol oxidation, ${ }^{51}$ and the oxygen reduction reaction. ${ }^{49,52}$ The oxygen vacancies of the OMS-2 catalysts explain quite well their catalytic combustion activities.

The activation of oxygen is important for the oxidation reaction..$^{53}$ Based on the $\mathrm{O}_{2}$-TPD results, the HAc-OMS-2 has the lowest desorption temperature of oxygen species, meaning that its oxygen species could be more readily released. The surface lattice oxygen related with $\mathrm{Mn}$ (III) is considered to play a key role in the catalytic oxidation reaction. ${ }^{46}$ The HAc-OMS-2 demonstrates the superior oxygen species mobility, resulting in an outstanding performance for DME and toluene combustion. Similar results have been reported for phenyl volatile organic compounds combustion over $\mathrm{MnO}_{x}$ catalyst. ${ }^{53}$

The surface adsorbed oxygen species have higher mobility than the lattice oxygen, thus contributing a lot to the catalytic performance at low temperature. ${ }^{10,40}$ The more the surface adsorbed oxygen, the better the catalytic activity. Based on the $\mathrm{O}$ $1 \mathrm{~s}$ results, the $\mathrm{O}_{\text {ads }} / \mathrm{O}_{\text {latt }}$ molar ratios of the catalysts decreased in the order of HAc-OMS-2 (0.76) > OMS-2 (0.58) > KOH-OMS-2 (0.27), which is in good agreement with the sequence of the catalytic combustion activities (HAc-OMS-2 > OMS- $2>\mathrm{KOH}-$ OMS-2). The importance of the surface adsorbed oxygen species 
have also been addressed in the catalytic decomposition of gaseous ozone, ${ }^{\mathbf{4 1}}$ formaldehyde oxidation, ${ }^{\mathbf{4 6}} \mathrm{CO}$ oxidation, ${ }^{\mathbf{4 4 , 5 5}}$ acetaldehyde oxidation, ${ }^{10}$ and toluene oxidation. ${ }^{56,57}$

3.2.3 Acidity. It is reported that the presence of strong acidity favors for the breakdown of $\mathrm{C}-\mathrm{C}$ bonds,${ }^{58}$ therefore, the appropriate rise in the surface acidity of the OMS- 2 catalyst will benefit the catalytic combustion. Based on the $\mathrm{NH}_{3}$-TPD result in Fig. 5, the strong acid in HAc-OMS-2 catalyst improved compared with the other two catalysts, whereas the strong acid in $\mathrm{KOH}-\mathrm{OMS}-2$ decreased. The concentration sequence of the strong acid agrees well with their combustion activity. He et al. ${ }^{58}$ also reported that, compared to the origin OMS-2, the doping of $\mathrm{SO}_{4}{ }^{2-}$ over OMS-2 increase the acidic site concentration, and further leading to a rise in catalytic combustion of ethanol. Suib et $a .^{42}$ reported that OMS-2 has Lewis and Brönsted acid sites, and the Brönsted acid sites are able to enhance the total oxidation of CO and VOCs. Also, it is reported that the potassium could partially neutralized the acid sites. ${ }^{59}$ In case of this study, the $\mathrm{KOH}$ treatment inhibited the Brönsted acid sites of the OMS-2, therefore, the $\mathrm{KOH}-\mathrm{OMS}-2$ has poor performance for catalytic combustion of DME and toluene.

3.2.4 The effect of $\mathbf{K}^{+}$. Alkali metals, especially the $\mathrm{K}$, are often used as promoters to enhance the catalytic activity of materials. ${ }^{59,60} \mathrm{Qu}$ et al. ${ }^{61}$ reported that a proper content of $\mathrm{K}^{+}$can enhance the reactivity of $\mathrm{Mn} / \mathrm{SBA}-15$ in the toluene catalytic oxidation. Li et $a .^{28}$ also reported that increasing the $\mathrm{K}^{+}$ concentration leads to a considerable improvement in benzene oxidation over OMS-2 catalyst. However, there are different study results about the role of $\mathrm{K}^{+}$. For example, Zhang et al. ${ }^{9}$ concluded that the $\mathrm{K}^{+}$concentration is not the dominate factor determining the activity of $\mathrm{MnO}_{2}$ catalyst for $\mathrm{HCHO}$ oxidation. Partial exchange of $\mathrm{K}^{+}$in the tunnel of OMS- 2 with $\mathrm{H}_{3} \mathrm{O}^{+}$can improve the selective oxidation of cyclohexane. ${ }^{31}$ In our case, the HAc-OMS-2 with the lowest content of $\mathrm{K}^{+}$presents the best activity, and the $\mathrm{KOH}-\mathrm{OMS}-2$ with the highest contend of $\mathrm{K}^{+}$ shows the worst activity. It is considered consequently that we propose that the role of $\mathrm{K}^{+}$might be not as important as other factors affecting the catalytic combustion activities.

3.2.5 Apparent activation energies $\left(\boldsymbol{E}_{\mathbf{a}}\right)$. The $E_{\mathrm{a}}$ values of DME and toluene combustion were calculated using the Arrhenius plots in Fig. $7 \mathrm{~b}$ and d, respectively, and were listed in Table 2. The $E_{\mathrm{a}}$ for DME combustion decreases in the sequence of KOH-OMS-2 (72.4 kJ mol $\left.{ }^{-1}\right)>$ OMS-2 $\left(70.4 \mathrm{~kJ} \mathrm{~mol}^{-1}\right)>\mathrm{HAc}^{-}$ OMS-2 (64.7 kJ mol$\left.{ }^{-1}\right)$. Similarly, the $E_{\mathrm{a}}$ for toluene combustion drops in an order of KOH-OMS-2 (68.0 $\left.\mathrm{kJ} \mathrm{mol}^{-1}\right)>$ OMS-2 (66.3 $\left.\mathrm{kJ} \mathrm{mol}^{-1}\right)>$ HAc-OMS-2 $\left(62.4 \mathrm{~kJ} \mathrm{~mol}^{-1}\right)$. In both cases, the $E_{\mathrm{a}}$ value of HAc-OMS-2 sample is found to be the lowest among the three catalysts. The lower $E_{\mathrm{a}}$ value suggests that the combustion reaction can take place more readily over the HAc-OMS-2 catalyst, which is the proof that the HAc-OMS-2 has the superior catalytic performance.

Briefly, the acid treatment is an effective approach to enhance the catalytic combustion of OMS-2 material. In fact, if we substitute $\mathrm{HAc}$ with $\mathrm{HCl}$, similar result can be obtained (the activity, the redox properties, ESI, Fig. S2-S5 $\dagger$ ). This result show that we could use inorganic acid to etch OMS-2 achieving the purpose of the control of catalytic activity.

\section{Conclusion}

In summary, the acid and alkali treated OMS-2 materials were prepared and evaluated as the catalysts for DME and toluene combustion. The acid treatment significantly enhanced the catalytic performance, whereas, the alkali treatment decreased the catalytic activity. The HAc-OMS-2 catalyst had richer surface oxygen, higher oxygen mobility and redox activity, and stronger acidic sites, leading to an improvement on the catalytic combustion activity. The acid etching/dissolution might be an effective way to enhance the catalytic activity of manganese oxides or other metal oxides.

\section{Acknowledgements}

This work was financially supported by the National Natural Science Foundation of China $(21306026,21576054)$, the Scientific Program of Guangdong Province (2014A010106030, 2016A010104017, 2016B020241003), the Foundation of Higher Education of Guangdong Province (2015KTSCX027).

\section{References}

1 S. L. Suib, Acc. Chem. Res., 2008, 41, 479-487.

2 Y. Q. Deng, T. Zhang, C. T. Au and S. F. Yin, Appl. Catal., A, 2013, 467, 117-123.

3 S. Liu, X. Liu, J. Zhao, Z. Tong, J. Wang, X. Ma, C. Chi, D. Su, X. Liu and Y. Li, RSC Adv., 2016, 6, 85222-85229.

4 C. Ji, H. Ren and S. Yang, RSC Adv., 2015, 5, 21978-21987.

5 H. C. Genuino, M. S. Seraji, Y. T. Meng, D. Valencia and S. L. Suib, Appl. Catal., B, 2015, 163, 361-369.

6 J. Jia, P. Zhang and L. Chen, Catal. Sci. Technol., 2016, 6, 5841-5847.

7 M. Özacar, A. S. Poyraz, H. C. Genuino, C.-H. Kuo, Y. Meng and S. L. Suib, Appl. Catal., A, 2013, 462-463, 64-74.

8 L. Wang, Y. Wu, N. Feng, J. Meng, H. Wan and G. Guan, RSC Adv., 2016, 6, 50288-50296.

9 J. H. Zhang, Y. B. Li, L. Wang, C. B. Zhang and H. He, Catal. Sci. Technol., 2015, 5, 2305-2313.

10 Y. Li, Z. Fan, J. Shi, Z. Liu, J. Zhou and W. Shangguan, Catal. Today, 2015, 256, 178-185.

11 C. Almquist, M. Krekeler and L. Jiang, Chem. Eng. J., 2014, 252, 249-262.

12 J. Hou, Y. Li, M. Mao, X. Zhao and Y. Yue, Nanoscale, 2014, 6, 15048-15058.

13 H. Sun, S. Chen, P. Wang and X. Quan, Chem. Eng. J., 2011, 178, 191-196.

14 V. P. Santos, S. S. T. Bastos, M. F. R. Pereira, J. J. M. Órfão and J. L. Figueiredo, Catal. Today, 2010, 154, 308-311.

15 H. Sun, Z. Liu, S. Chen and X. Quan, Chem. Eng. J., 2015, 270, 58-65.

16 Y. Yang, J. Huang, S. Z. Zhang, S. W. Wang, S. B. Deng, B. Wang and G. Yu, Appl. Catal., B, 2014, 150, 167-178.

17 V. P. Santos, M. F. R. Pereira, J. J. M. Orfao and J. L. Figueiredo, Appl. Catal., B, 2009, 88, 550-556. 
18 V. P. Santos, O. S. G. P. Soares, J. J. W. Bakker, M. F. R. Pereira, J. J. M. Órfão, J. Gascon, F. Kapteijn and J. L. Figueiredo, J. Catal., 2012, 293, 165-174.

19 Y. Wu, R. Feng, C. Song, S. Xing, Y. Gao and Z. Ma, Catal. Today, 2017, 281, 500-506.

20 H. Yin, X. Dai, M. Zhu, F. Li, X. Feng and F. Liu, J. Hazard. Mater., 2015, 296, 221-229.

21 X. Meng, J. Q. Zhang, B. H. Chen, Z. Q. Jing and P. Q. Zhao, Catal. Sci. Technol., 2016, 6, 890-896.

22 L. L. Zhang, J. J. Tu, L. Lyu and C. Hu, Appl. Catal., B, 2016, 181, 561-569.

23 V. P. Santos, S. A. C. Carabineiro, J. J. W. Bakker, O. S. G. P. Soares, X. Chen, M. F. R. Pereira, J. J. M. Órfão, J. L. Figueiredo, J. Gascon and F. Kapteijn, J. Catal., 2014, 309, 58-65.

24 M. Sun, L. Yu, F. Ye, G. Q. Diao, Q. Yu, Z. F. Hao, Y. Y. Zheng and L. X. Yuan, Chem. Eng. J., 2013, 220, 320-327.

25 G. D. Yadav and R. K. Mewada, Catal. Today, 2012, 198, 330337.

26 M. Ousmane, G. Perrussel, Z. Yan, J. M. Clacens, F. De Campo and M. Pera-Titus, J. Catal., 2014, 309, 439-452.

27 T. Zhang, Y. Q. Deng, W. F. Zhou, C. T. Au and S. F. Yin, Chem. Eng. J., 2014, 240, 509-515.

28 J. Hou, L. Liu, Y. Li, M. Mao, H. Lv and X. Zhao, Environ. Sci. Technol., 2013, 47, 13730-13736.

29 Y. Yuan, C. Zhan, K. He, H. Chen, W. Yao, S. Sharifi-Asl, B. Song, Z. Yang, A. Nie, X. Luo, H. Wang, S. M. Wood, K. Amine, M. S. Islam, J. Lu and R. Shahbazian-Yassar, Nat. Commun., 2016, 7, 13374.

30 J. Liu, V. Makwana, J. Cai, S. L. Suib and M. Aindow, J. Phys. Chem. B, 2003, 107, 9185-9194.

31 R. Kumar, S. Sithambaram and S. L. Suib, J. Catal., 2009, 262, 304-313.

32 W. Si, Y. Wang, Y. Peng and J. Li, Angew. Chem., Int. Ed., 2015, 54, 7954-7957.

33 Y. Peng, W. Si, J. Luo, W. Su, H. Chang, J. Li, J. Hao and J. Crittenden, Environ. Sci. Technol., 2016, 50, 6442-6448.

34 F. Liang, Y. Yu, W. Zhou, X. Xu and Z. Zhu, J. Mater. Chem. A, 2015, 3, 634-640.

35 Q. Hua, D. Shang, W. Zhang, K. Chen, S. Chang, Y. Ma, Z. Jiang, J. Yang and W. Huang, Langmuir, 2011, 27, 665-671.

36 H. Zhou, B. Lv, L. Wang, D. Wu and Y. Xu, CrystEngComm, 2015, 17, 1848-1855.

37 W. Hu, J. Lan, Y. Guo, X.-M. Cao and P. Hu, ACS Catal., 2016, 6, 5508-5519.

38 R. Jothiramalingam, B. Viswanathan and T. K. Varadarajan, Catal. Commun., 2005, 6, 41-45.
39 J. Hou, Y. Li, M. Mao, L. Ren and X. Zhao, ACS Appl. Mater. Interfaces, 2014, 6, 14981-14987.

40 V. P. Santos, M. F. R. Pereira, J. J. M. Orfao and J. L. Figueiredo, Appl. Catal., B, 2010, 99, 353-363.

41 J. B. Jia, P. Y. Zhang and L. Chen, Appl. Catal., B, 2016, 189, 210-218.

42 J. Luo, Q. Zhang, J. Garcia-Martinez and S. L. Suib, J. Am. Chem. Soc., 2008, 130, 3198-3207.

43 L. Sun, Q. Cao, B. Hu, J. Li, J. Hao, G. Jing and X. Tang, Appl. Catal., A, 2011, 393, 323-330.

44 V. R. Galakhov, M. Demeter, S. Bartkowski, M. Neumann, N. A. Ovechkina, E. Z. Kurmaev, N. I. Lobachevskaya, Y. M. Mukovskii, J. Mitchell and D. L. Ederer, Phys. Rev. B: Condens. Matter Mater. Phys., 2002, 65, 1131021-1131024.

45 E. C. Njagi, C. H. Chen, H. Genuino, H. Galindo, H. Huang and S. L. Suib, Appl. Catal., B, 2010, 99, 103-110.

46 Z. Wang, W. Z. Wang, L. Zhang and D. Jiang, Catal. Sci. Technol., 2016, 6, 3845-3853.

47 Q. Ye, H. Lu, J. Zhao, S. Cheng, T. Kang, D. Wang and H. Dai, Appl. Surf. Sci., 2014, 317, 892-901.

48 J. Hou, Y. Li, L. Liu, L. Ren and X. Zhao, J. Mater. Chem. A, 2013, 1, 6736.

49 F. Cheng, T. Zhang, Y. Zhang, J. Du, X. Han and J. Chen, Angew. Chem., Int. Ed., 2013, 52, 2474-2477.

50 D. A. Tompsett, S. C. Parker and M. S. Islam, J. Am. Chem. Soc., 2014, 136, 1418-1426.

51 L.-C. Wang, Y.-M. Liu, M. Chen, Y. Cao, H.-Y. He and K.-N. Fan, J. Phys. Chem. C, 2008, 112, 6981-6987.

52 L. Li, X. H. Feng, Y. Nie, S. G. Chen, F. Shi, K. Xiong, W. Ding, X. Q. Qi, J. S. Hu, Z. D. Wei, L. J. Wan and M. R. Xia, ACS Catal., 2015, 5, 4825-4832.

53 G. L. Zhou, H. Lan, H. Wang, H. M. Xie, G. Z. Zhang and X. X. Zheng, J. Mol. Catal. A: Chem., 2014, 393, 279-288.

54 P. Venkataswamy, K. N. Rao, D. Jampaiah and B. M. Reddy, Appl. Catal., B, 2015, 162, 122-132.

55 Q. Ye, J. Zhao, F. Huo, D. Wang, S. Cheng, T. Kang and H. Dai, Microporous Mesoporous Mater., 2013, 172, 20-29.

56 F. Wang, H. Dai, J. Deng, G. Bai, K. Ji and Y. Liu, Environ. Sci. Technol., 2012, 46, 4034-4041.

57 F. Shi, F. Wang, H. Dai, J. Dai, J. Deng, Y. Liu, G. Bai, K. Ji and C. T. Au, Appl. Catal., A, 2012, 433-434, 206-213.

58 J. Zhang, C. Zhang and H. He, J. Environ. Sci., 2015, 35, 6975.

59 K. Jirátová, J. Mikulová, J. Klempa, T. Grygar, Z. Bastl and F. Kovanda, Appl. Catal., A, 2009, 361, 106-116.

60 B. Y. Bai and J. H. Li, ACS Catal., 2014, 4, 2753-2762.

61 Z. P. Qu, Y. B. Bu, Y. Qin, Y. Wang and Q. Fu, Chem. Eng. J., 2012, 209, 163-169. 